\title{
PAX TURANA. К ВОПРОСУ О СТАНОВЛЕНИИ ДРЕВНЕТЮРКСКОЙ ЦИВИЛИЗАЦИИ
}

\section{Шарипов Ренарт Глюсович}

кандидат философских наук, научный сотрудник отдела этнологии Институт истории языка и литературы

Уфимского федерального исследовательского центра Российской академии наук (УФИЦ РАН)

Аннотация: Данная статья посвящена такой важной и малоизученной проблеме как история цивилизации древних тюрков, реально существовавшая в VI-XI вв. и охватывавшая внутренние просторы Евразийского материка. В вопросах происхождения тюркских народов до сих пор существуют белые пятна. Тем не менее, опираясь на имеющиеся сведения и исследования советских, западных и современных мировых ученых, можно попытаться реконструировать более или менее связную историческую картину развития Тюркской цивилизации степного пояса Евразии в эпоху раннего средневековья. Наличие таких весомых маркеров, как развитое мировоззрение, общественно-политическая мысль и литература, зафиксированные в письменных носителях, дошедших, что как нельзя более ценно, до нашего времени, наталкивают на мысль о корреляции процессов развития древнетюркской государственности и эволюции духовной культуры тюркских номадов первого тысячелетия н.э. Анализ древнетюркской культуры эпохи каганатов заставляет прийти к выводу о довольно высоком уровне развития философских, политических и религиозных воззрений, которым сопутствовала широко распространенная письменная грамотность на основе рунического письма и приобщенность населения к другим достижениям цивилизации.

Ключевые слова: Pax Turana, Тюркская цивилизация, Эпоха Каганатов, Тюркская руника, эволюция духовной культуры тюркских номадов. 


\title{
PAX TURANA. TO THE QUESTION OF FORMATION OF ANCIENT TURKIC CIVILIZATION
}

\section{Renart Glusovich Sharipov}

\begin{abstract}
This article is devoted to such an important and little-studied problem as the history of the civilization of the ancient Turks, which really existed in the VI-XI centuries and covered the inner expanses of the Eurasian continent. There are still white spots in the issues of the origin of the Turkic peoples. Nevertheless, based on the available information and research of Soviet, Western and modern world scientists, it is possible to try to reconstruct a more or less coherent historical picture of the development of the Turkic civilization of the steppe belt of Eurasia in the early Middle Ages. The presence of such weighty markers as a developed worldview, socio-political thought and literature, recorded in written media that have come down to our time, which is as valuable as possible, suggests the idea of a correlation between the processes of development of ancient Turkic statehood and the evolution of the spiritual culture of the Turkic nomads of the first millennium AD. The analysis of the ancient Turkic culture of the Khaganats era leads to the conclusion about a fairly high level of development of philosophical, political and religious views, which were accompanied by widespread written literacy based on runic writing and the familiarity of the population with other achievements of civilization.
\end{abstract}

Keywords: Pax Turana, Turkic civilization, the Era of the Khaganats, the Turkic Runic, the evolution of the spiritual culture of the Turkic nomads.

Большинство данных используемых при реконструкции материальной и духовной культуры кочевников пояса Великих степей Евразии эпохи раннего средневековья - это разрозненные, а порой и противоречащие друг другу свидетельства, почерпнутые из арабских, иранских, древнерусских, западноевропейских и китайских источников. Возможно, именно по этой причине в вопросах происхождения тюркских народов до сих пор существуют белые пятна. Тем не менее, опираясь на имеющиеся сведения и исследования современных ученых, можно попытаться реконструировать более или менее связную историческую картину развития тюркской цивилизации степного пояса Евразии в эпоху раннего средневековья. 
В наших предыдущих работах мы постарались обосновать тезис о реальном существовании в историческом пространстве особой культурной ойкумены - единого Pax Turana, которая на протяжении целого ряда веков охватывала внутренние просторы Евразийского материка. [1].

На протяжении одного-двух тысячелетий государственные образования древних тюрков проделали огромный путь от племенных союзов, названия которых походя упоминаются древнекитайскими хрониками среди прочих «варваров», и до величественных империй, о которых с почтением говорили как на восточных, так и на крайних западных рубежах евразийского материка.

Как великая китайская цивилизация в Юго-Восточной Азии и римская цивилизация в Западной Европе, цивилизация древних тюрков на протяжении многих веков играла консолидирующую роль в глубинных районах Евразии.

Важной вехой в истории цивилизации древних тюрков следует считать период раннего средневековья - VI-VIII вв. н.э. Именно в это время закладывались основы древнетюркской государственности, достигли своего наивысшего расцвета грандиозные кочевые империи - каганаты.

Роль, которую сыграли Первый и Второй Тюркский каганаты в исторических судьбах тюркской этнокультурной общности, неоценима. Степные империи тюркютов впервые в истории средневековья объединили в рамках единого государства большинство тюркоязычных этносов. Дружбы с тюркскими каганами искали даже византийцы. Неоценимо значение каганатов в консолидации тюркоязычных племен, и многие из них, такие как уйгуры, карлуки, огузы, кимаки, болгары, хазары, вписавшие немало страниц в историю евразийских степей и положившие начало многим современным народам Европы и Азии, основной заряд своей этнической, политической и культурной активности получили именно в момент, когда все они плавились в одном огромном тигле, имя которому - Империя Тюрков.

Завоевательные походы Первого и Второго Тюркских каганатов распространили на необъятные территории - от Великой Китайской стены до рубежей Византии - общие культурные традиции, как в материальной, так и в духовной сферах, засвидетельствованные целым рядом источников. Следует отметить, что эти складывавшиеся на протяжении веков общие мировоззренческие категории явились предпосылками к осознанию этнического и культурного единства древнетюркских племен, что, в конечном счете, привело к созданию тюркских империй, в границах которых происходят полная консолидация и становление древнетюркской цивилизации. В эту эпоху среди 
тюркских номадов Азии и Восточной Европы распространяются общие идеалы государственного строительства, широкое распространение получает руническая письменность [там же].

Наличие собственной уникальной письменной системы, как известно, является «визитной карточкой» любой крупной цивилизации. Л.Н. Гумилев, развивая тезис Энгельса о варварстве и цивилизации, в своем монументальном труде «Древние тюрки» отмечал, что «высшая ступень варварства, как известно, начинается с плавки железной руды и переходит в цивилизацию в результате изобретения буквенного письма и применения его для записывания словесного творчества» [2; с. 63].

В настоящий момент существует множество версий происхождения рунической письменности, большинство из них стараются объяснить феномен древнетюркской руники как нечто заимствованное. Однако, как бы там ни было, существование собственной письменности у древнетюркских номадов раннего средневековья и, более того, широкое распространение письменной грамотности в их среде свидетельствуют о достаточно высоком уровне развития степной цивилизации древних тюрков, что ставит ее в один ряд с другими евроазиатскими цивилизациями, существовавшими и развивавшимися в ту же историческую эпоху. Древние тюрки эпохи каганатов, так же как и их ближайшие соседи, имели развитое мировоззрение и общественно-политическую мысль [3].

Наличие таких весомых маркеров, как развитое мировоззрение, общественно-политическая мысль и литература, зафиксированные в письменных носителях, дошедших, что как нельзя более ценно, до нашего времени, наталкивают на мысль о корреляции процессов развития древнетюркской государственности и эволюции духовной культуры тюркских номадов первого тысячелетия н.э.

Между тем оценки государственности древних тюрков со стороны ряда исследователей выглядят довольно предвзято.

Долгое время в европейской науке бытовало расхожее мнение о том, что грандиозные империи номадов создавались в одночасье, по царственному капризу талантливого вождя, практически на пустом месте, возникая из «небытия» первобытной стихии. Примерно таким образом охарактеризовал Р. Хенниг становление Великого Тюркского каганата: «Подобно тому, как в 13 и 14 вв. чуть ли не за одну ночь вырастали гигантские монгольские державы Чингисхана и Тимур-ленга, так и вождь одной тюркской орды - тюкуэ - создал с 
553 г. в Центральной Азии огромную державу, которая одно время простиралась от Кавказа и Азовского моря до Тихого океана...» [4; с. 88]. При этом автор совершенно упускает из виду, что государства подобного уровня, как Тюркские каганаты, империи Чингиза и Тамерлана, просто никак не могли вырасти «за одну ночь», что их возникновению предшествовали длительные глубинные процессы внутренней консолидации этносов, проходившие в своем развитии различные этапы становления государственности, а также совершает ошибку, ставя на один уровень все эти образования, не задумываясь над тем, что при внешнем сходстве все эти империи имели разную судьбу и создавались при несхожих исторических условиях.

Учитывая естественную мобильность номадических сообществ, для которых, в отличие от большинства оседлых культур, был свойствен интенсивный путь становления государственности, необходимо отличать ее от ложных представлений об империях, выросших якобы за одну ночь. Следует учитывать, что эволюция тюркских государств, несмотря на ее специфику, происходила примерно по тому же пути, что и в других обществах.

Бесспорно, нельзя видеть в Тюркских каганатах и государствах, подхвативших их историко-культурную эстафету, явление спорадическое, случайное.

К сожалению, и советская наука, внесшая свой весомый вклад в изучение тюркских народов и их предков, создав огромный задел для дальнейших исследований в области истории материальной культуры, языкознании и литературоведении - трех главных китов, на которых до недавнего времени зиждилось здание классической тюркологической школы, тем не менее, не избегла шор европоцентризма и предвзятого подхода к истории тюркской этнокультурной общности.

Пытаясь вогнать историю кочевников Евразии в рамки Марксова учения об общественно-экономических формациях и упорно распространяя мерило классовости на все явления культуры - равно материальной, как и духовной, советская тюркологическая школа стремилась рассмотреть феномен степной древнетюркской культуры как явление, в целом так и не преодолевшее рубежа, отделяющего первобытность от развитых «цивилизованных» обществ, и застывшее на стадии «варварства» (по классификации Моргана - Энгельса) [5; 6]

Особенно это характерно для трудов советских историков сталинской эпохи. Крупный исследователь Л.П. Потапов, например, считал Тюркский каганат «...непрочным военно-административным объединением, временным 
союзом различных кочевых племен под гегемонией тюркских каганов, не имевших своей экономической базы» [7; с. 94]. Примерно такую же оценку дает Е.М. Мелетинский: «...тюркоязычные племена вплотную подошли в своем развитии к феодальной государственности, но в силу специфических исторических условий так и не поднялись выше мощных племенных союзов» [8; c. 251].

Между тем беспристрастный анализ древнетюркской культуры эпохи каганатов заставляет прийти к выводу о довольно высоком уровне развития философских, политических и религиозных воззрений, которым сопутствовала широко распространенная письменная грамотность и приобщенность населения к другим достижениям цивилизации, что довольно удивительно, если продолжать считать древних тюрков к моменту создания каганатов (то есть к середине 1-го тысячелетия н.э.) только что вышедшими из колыбели первобытного мира.

Нелишне было бы упомянуть и о степных государствах предшественниках великих каганатов. В хронологическом и территориальном масштабах мы можем обнаружить, даже если и не прямых, то хотя бы косвенных предшественников тюркских империй, существовавшие примерно на той же территории в IV-I вв. до н. э. племенные союзы (а практически - государства) Хунну, Усунь, Кангюй. На данном этапе развития науки мы можем с уверенностью называть эти ранние государства «предками» каганатов, тем более, что в эпоху классических тюрков все три видоизменившиеся образования входили в состав империй на правах федератов и вассалов. Так, например, Кангюй был известен как «западный рубеж» тюркской державы под наименованием Кангу Тарбан [9; с. 155-179]. Усунь входила в состав практически всех тюркских каганатов как Уйсын, Хушин (монгольская форма) и в форме племенного подразделения дожила практически до наших дней. От легендарного уйсынского (усуньского) бия Майкы ведут свою генеалогию многие роды в составе башкир, татар, казахов, кыргызов и др. современных тюркских народов [10].

В период смены парадигм научного знания, произошедшей (правда, так и не достигнув логического конца) за последние тридцать лет, необходимо признать ситуацию в современной отечественной тюркологии весьма плачевной. Если в сфере антропологии, археологии и языкознания наука продолжает свое поступательное развитие, то в сфере теоретических исследований наблюдается очевидный застой. Часть ученых продолжает цепляться за отжившие 
представления советской «классической» школы, а попытки других преодолеть предвзятое мнение о тюрках и кочевниках в целом, увели их в сторону лженауки или, в лучшем случае, околонаучной фантастики. Таким образом, необходимость создания новой и стройной тюркологической теории совершенно очевидна.

Мы пришли к выводу, что древние тюрки:

1. Имели свою собственную уникальную культурную традицию.

2. Имели свои государства, которые сыграли немаловажную роль в формировании современных государств Европы и Азии.

3. Имели свою уникальную религию и мифологию, связь с которыми до сих пор прослеживается у многих народов мира.

4. Имели свою письменность, иитературу общественно-политическую мысль.

5. Обладали развитым мировоззрением, которое нашло свое отражение в объектах материальной культуры и искусства.

6. Духовная культура, созданная древнетюркской цивилизацией, имеет свое продолжение и развитие в духовной жизни современных тюркских народов и других народов Евразии, которая не может быть проигнорирована. [1, с. 149].

\section{Список литературы}

1. Шарипов Р.Г. Духовная культура древнетюркской цивилизации. Менталитет. Религия. Искусство. Эпос. Уфа, Издательство ИИЯЛ УНЦ РАН, 2015. -154 c.

2. Гумилев Л.Н. Древние тюрки. М., Клышников, Комаров и К일. 1993. 497 c.

3. Шарипов Р.Г. Рунические тексты эпохи каганатов как источник изучения цивилизации древних тюрков.// Ядкар («Наследие»), 2006. № 2. C. 60-62.

4. Хенниг Р. Неведомые земли. Издательство иностранной литературы, T I, M., 1961. - $516 \mathrm{c}$.

5. Морган Л.Г. Древнее общество или исследование человеческого прогресса от дикости через варварство к цивилизации. Л., Издательство Института истории народов Севера ЦИК СССР, 1934. - 350 с. 
6. Энгельс Ф. Возникновение семьи, частной собственности и государства. М., Издательство политической литературы, 1980. - 238 с.

7. Потапов Л.П. Очерки по истории алтайцев. М.,Л., Издательство Академии Наук СССР, 1953. - 444 с.

8. Мелетинский Е.М. Происхождение героического эпоса. М., Издательство восточной литературы, 1963. - 462 с.

9. Кляшторный С.Г. Древнетюркские рунические памятники. М., Наука, 1964. - 215 с.

10. Сулейманов М.-Х. Майкы-бий, учение «Жасау-ізі» и истоки чингизизма. История народов Турана в преданиях казахских биев. Алматы, Service press, 2013. -279 c. 